Check for updates

Cite this: RSC Adv., 2018, 8, 39170

\title{
A new method for electrodeposition of Al coatings from ionic liquids on AZ91D Mg alloy in air
}

\author{
Ding Zhang, ${ }^{a}$ Yanguang Mu, ${ }^{a}$ Haipu Li, (D) *a Zhaoguang Yang ${ }^{\text {ab }}$ and Ying Yang ${ }^{* a}$ \\ Electrodeposition of Al on Mg alloys from ionic liquids has been achieved scientifically. However, it is \\ difficult to realize industrialized production since the preparation of electroplating bath and \\ electrodeposition process must be carried out under inert atmosphere. A simple and practical method \\ was then proposed to guarantee such manipulations in air by introducing a solid water-adsorbent \\ material as well as a liquid protective film in electroplating bath. In the experimental scale, functional $\mathrm{Al}$ \\ layers were successfully electrodeposited on AZ91D Mg alloys from a first-generation ionic liquid $\mathrm{AlCl}_{3} /$ \\ 1-butyl-3-methylimidazolium chloride (2:1 mol\%). The electroplating process was further investigated at \\ constant current and constant potential. A phase of Al of the formed coatings was determined using X- \\ ray diffraction. It was found that a continuous and compact Al film can be obtained on the Mg alloy \\ surface at a constant current along with effective protection, as characterized by scanning electron \\ microscopy, energy disperse spectrometry, potentiodynamic polarization curve and Nyquist plot.
}

Received 19th September 2018

DOI: $10.1039 / \mathrm{c} 8 \mathrm{ra07788f}$

rsc.li/rsc-advances

electrodeposition. Under this dual protection, the electrodeposition of $\mathrm{Al}$ coatings on AZ91D Mg alloy was performed at the designated current and potential to investigate the effect and degree of the proposed treatment method.

$\mathrm{Mg}$ and its alloys have been considered as some of the most promising materials in recent years due to their advantageous mechanical properties and low density. ${ }^{1-3}$ To improve the corrosion resistance of $\mathrm{Mg}$ alloys, electrodeposition of chemically and mechanically protective Al coatings from ionic liquids has attracted both scientific and industrial curiosity. ${ }^{4-8}$ Most practices of electrodeposition of aluminum on $\mathrm{Mg}$ alloys are processed in an inert atmosphere, e.g., a glovebox owing to the high air and moisture sensitivity of common ionic liquids., ${ }^{3,9,10}$ This drawback has seriously limited the industrial production. Parallel to the exploration of air and water-stable ionic liquids in related fields, ${ }^{\mathbf{1 1}, 12}$ a way to protect working ionic liquids has been proposed. For example, using a nonwater-absorbable layer of a particular hydrocarbon compound, such as decane, has helped realize electrodeposition in air. Nevertheless, the preparation of ionic liquid bath still needs to be conducted in an argon-filled glove box. ${ }^{13}$ Is it possible to develop a simple and practical method to allow the whole procedure of electrodeposition of $\mathrm{Al}$ coatings on $\mathrm{Mg}$ alloys to be carried out in air?

In the current communication, a solid water-absorbent material was introduced into the mixture of $\mathrm{AlCl}_{3}$ and 1-butyl3-methylimidazolium chloride $([\mathrm{Bmim}] \mathrm{Cl})$ to investigate the possibility of the preparation of ionic liquid in air. In addition, undecane was used as the organic protective layer during

${ }^{a}$ College of Chemistry and Chemical Engineering, Central South University, Changsha 410083, PR China.E-mail: lihaipu@csu.edu.cn; yangy@csu.edu.cn

${ }^{b}$ Key Laboratory of Hunan Province for Water Environment and Agriculture Product Safety, Changsha 410083, PR China

\section{Experimental}

\subsection{Chemicals}

All employed chemicals were commercially available and used without further purification: 1-butyl-3-methylimidazolium chloride $([\mathrm{Bmim}] \mathrm{Cl})$ with chemical formula $\mathrm{C}_{8} \mathrm{H}_{15} \mathrm{ClN}_{2}$ (Aldrich, 99\%), aluminum chloride anhydrous (Aldrich, $\geq 99 \%$ ), and undecane (Aldrich, $\geq 99 \%$ ).

\subsection{Procedure}

$\mathrm{AlCl}_{3}$ and $[\mathrm{Bmim}] \mathrm{Cl}$ were mixed in a molar ratio of $2: 1$ at room temperature, ${ }^{\mathbf{1 4}, \mathbf{1 5}}$ followed by the addition of the waterabsorbent material (4A molecular sieve, around $10 \mathrm{wt} \%$ of ionic liquid). The mixture was then covered with undecane layer and stirred for $24 \mathrm{~h}$ to complete the reaction. Then, the resultant ionic liquid was transferred into an electrobath.

The electrodeposition was carried out with a conventional three-electrode cell on electrochemical workstation (CS310, Wuhan CorrTest Instruments Corp., Ltd.) at ambient temperature. High-purity Al sheets $(70 \times 20 \times 1 \mathrm{~mm})$ were used as anode, and a die-cast AZ91D Mg alloy sheet (9.02 wt\% Al and $0.49 \mathrm{wt} \% \mathrm{Zn})$ was used as cathode $(70 \times 20 \times 2 \mathrm{~mm})$. The area of working electrode was set as $6 \mathrm{~cm}^{2}$ as it was actually immersed in the electrolyte. The Al wire was connected as a reference electrode. Before electrodeposition, each metallic sample was ground with 1000-grit SiC papers, and the polished 
$\mathrm{Mg}$ alloy sheet was further treated with $10 \%$ phosphoric acid to prevent oxidation and to increase the adhesion strength.

Constant potential $(-0.67 \mathrm{~V}$ vs. the $\mathrm{Al}$ wire $)$ and constant current $(-30.08 \mathrm{~mA})$ were applied to investigate the deposition of aluminum. A schematic diagram of the experiment is shown below (Fig. 1).

\section{Results and discussion}

The electrodeposition process was performed potentiostatically or galvanostatically for $7500 \mathrm{~s}$ in each case (Fig. 2). As shown in Fig. 2a, the current density under $-0.67 \mathrm{~V}$ electrodeposition decreased rapidly at the beginning (0-300 s). In the first part of transition, a large cathodic current was observed due to sudden deposition of abundant $\mathrm{Al}$ ions to form nuclei on the surface of $\mathrm{Mg}$ alloy, and the subsequent decrease in current was caused by the formation of depletion layers of $\mathrm{Al}$ ions. The subsequent decrease in cathodic current was induced by nuclei growth, which enabled efficient collection of $\mathrm{Al}^{3+}$ ions due to the steric effect. The continuously decreasing deposition current indicated continuous growth of diffusion layers due to the higher rate of $\mathrm{Al}^{3+}$ ion consumption. ${ }^{\mathbf{1 6}}$ After that, the current density decreased steadily with electrodeposition time. This indicated that the $\mathrm{Mg}$ alloy was already covered with an Al coating, and the electrodeposition process changed to $\mathrm{Al}$ electroplating on the $\mathrm{Al}$ substrate.

When the cathode current was maintained at $-30.08 \mathrm{~mA}$ (Fig. 2b), the potential shifted rapidly from $-0.80 \mathrm{~V}$ to $-0.87 \mathrm{~V}$ during the first $130 \mathrm{~s}$. The large potential at the start of the transition might also be due to sudden deposition of $\mathrm{Al}$ to form nuclei; the subsequent increase in the cathodic potential was caused by nuclei growth. After the formation of a depletion layer of $\mathrm{Al}$, the deposition potential continuously decreased for the growth of the diffusion layer with a higher rate of $\mathrm{Al}$ ion consumption. Hereinafter, the Al coatings were formed and the

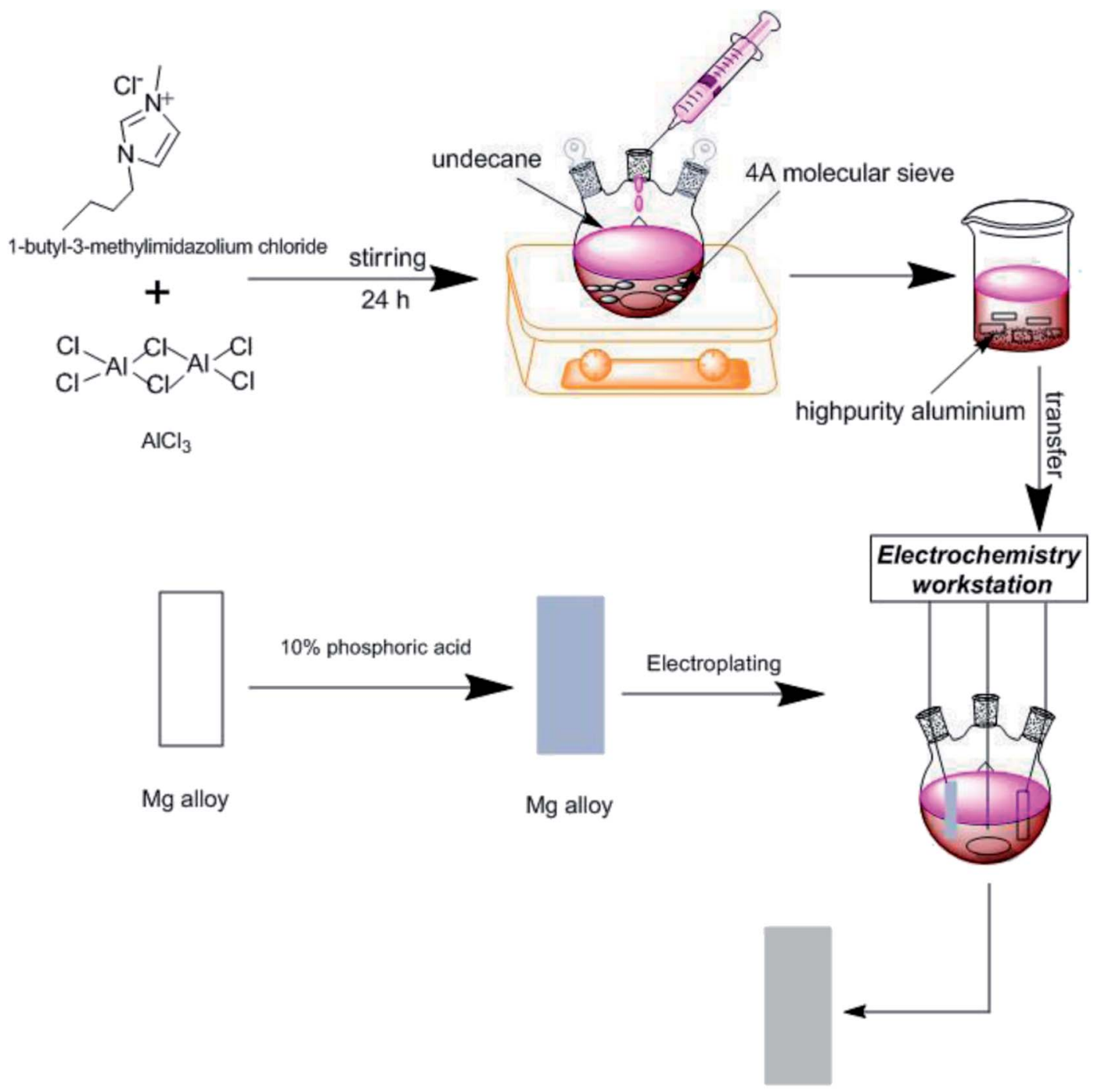

Al plating

Fig. 1 Scheme of the experimental process. 


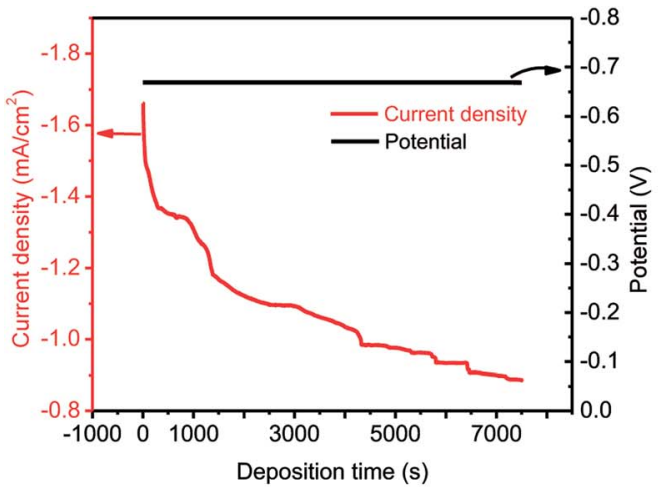

(a)

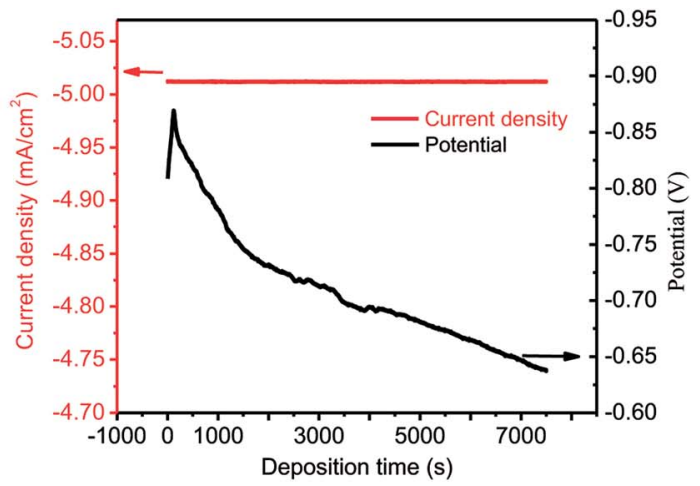

(b)

Fig. 2 Electrodeposition at $-0.67 \mathrm{~V}(\mathrm{a})$ and $-30.08 \mathrm{~mA}(\mathrm{~b})$ along with electrodeposition time.

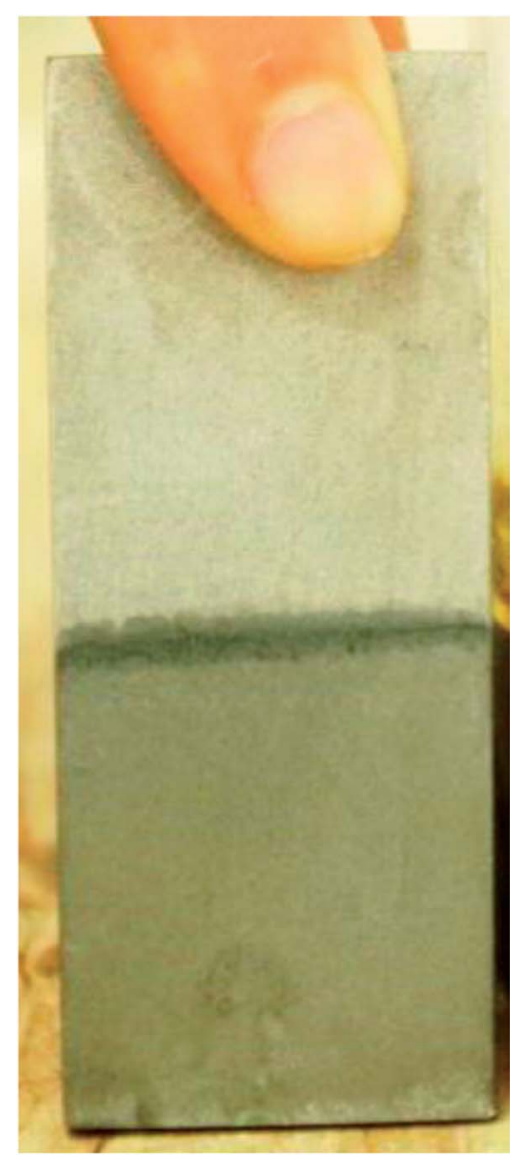

Fig. 3 Appearance of Al coating electroplated on $\mathrm{Mg}$ alloy strip obtained with constant current of $-30.08 \mathrm{~mA}$ with $7500 \mathrm{~s}$.

electrodeposition potential started to decline as a function of time. ${ }^{5,16}$

It can be found that the profiles of current density and potential change were different with constant potential and constant current density. The initial increasing potential obtained at constant current deposition was favorable for the formation of Al nuclei in the first part; the uniform nucleus arrangement at the starting determined the quality of the $\mathrm{Al}$ coating. As a comparison, the currents in constant potential deposition did not display a process of growth and then decline. This indicated that the formation of Al nuclei was insufficient.

The coatings obtained at a constant potential or constant current have similar appearance. One photograph of an Alelectroplated $\mathrm{Mg}$ alloy (AZ91D) strip from $\mathrm{AlCl}_{3} /[\mathrm{Bmim}] \mathrm{Cl}$ ionic liquid is shown in Fig. 3; it is obtained at a constant current of $-30.08 \mathrm{~mA}$ with $7500 \mathrm{~s}$.

To conduct detailed investigation on the difference between the samples obtained at either constant potential or constant current density, XRD was used to characterize the crystallinity of coatings (Fig. 4).

Characteristic diffraction peaks indicated that crystalline Al was deposited on both samples. Furthermore, the peaks of $\mathrm{Al}$ (111) of the two samples were explored to determine the grain size of the Al coatings. The full-width at half maximum (FWHM) values of the $\mathrm{Al}$ (111) peaks are displayed in Fig. 4. The grain sizes of $\mathrm{Al}$ coatings obtained with $-0.67 \mathrm{~V}$ constant potential and $-30.08 \mathrm{~mA}$ constant current were 42.5 and $41.0 \mathrm{~nm}$, respectively, which were calculated with the Scherrer's equation. ${ }^{17}$

The Al coatings obtained from ionic liquid in the glove box reported by N. Koura ${ }^{18}$ showed similar crystal forms. However, the grain sizes of Al coatings obtained in the present study were slightly larger than that of the $\mathrm{Al}$ coating $(32 \mathrm{~nm})$ prepared from the ionic liquid in the glove box by S. Zein El Abedin. ${ }^{17}$

The obtained Al coatings were also examined using a scanning electron microscope (SEM) (Philip XL-40FEG) and energy disperse spectrometer (EDS) (Oxford instruments X-Max) (Fig. 5).

Fig. 5a and $\mathrm{b}$ demonstrate the SEM images of the coatings obtained with $-0.67 \mathrm{~V}$ and $-30.08 \mathrm{~mA}$, respectively. Fig. 5c shows a high resolution SEM micrograph of Al coatings on an $\mathrm{Mg}$ alloy substrate electrodeposited at a constant potential of $-0.67 \mathrm{~V}$ for $7500 \mathrm{~s}$ at room temperature. It can be observed that there were fine cracks in the top coating, which may be due to internal or residual stress during electrodeposition, and this is 

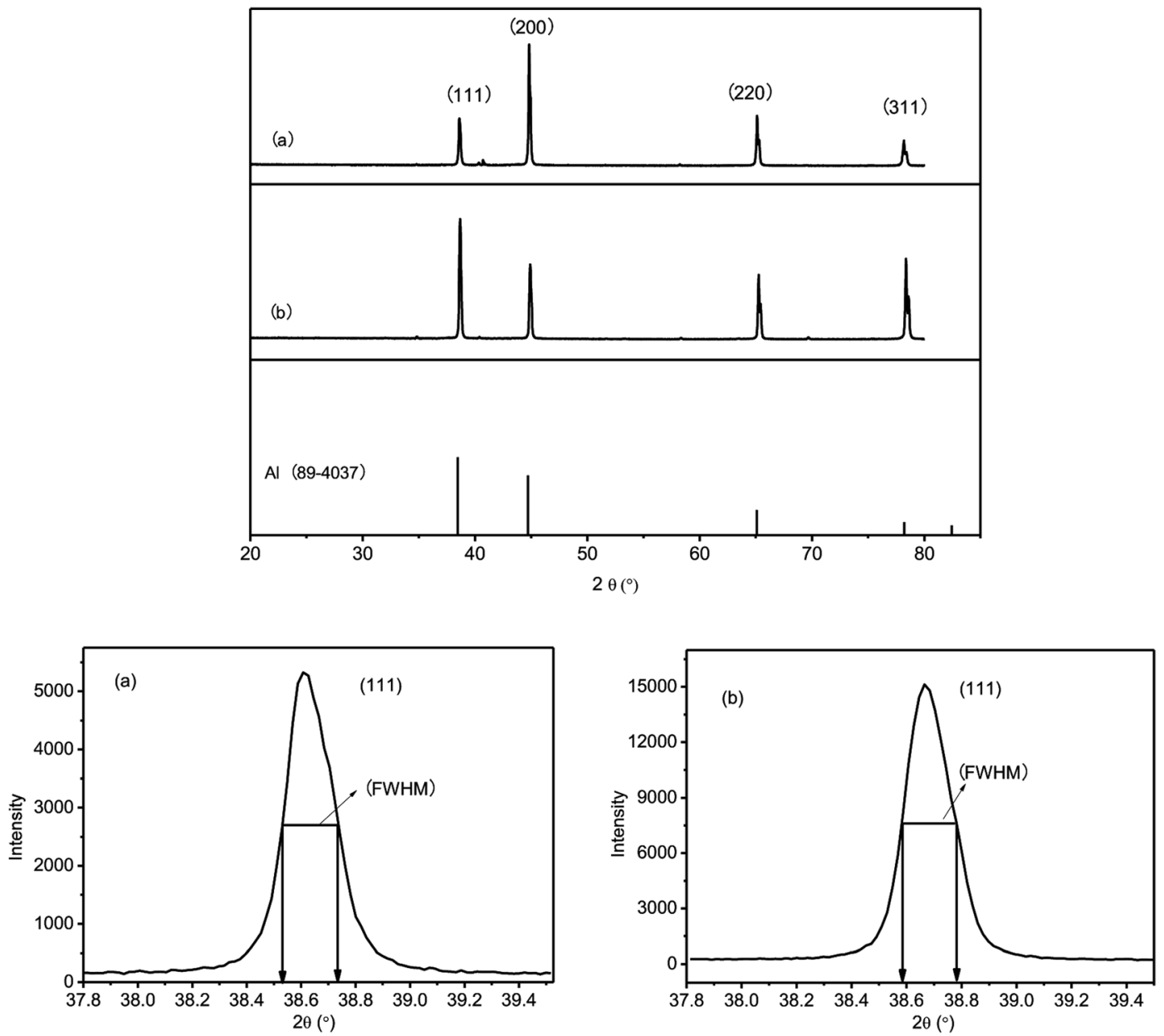

Fig. 4 X-ray diffraction patterns of coatings obtained with $-0.67 \mathrm{~V}(\mathrm{a})$ and $-30.08 \mathrm{~mA}$ (b).

disadvantageous for corrosion resistance, resulting in serious oxidation. ${ }^{19}$ In contrast, the electrodeposition at $-30.08 \mathrm{~mA}$ for $7500 \mathrm{~s}$ afforded a continuous and compact $\mathrm{Al}$ coating, as shown in Fig. $5 d$.

EDS analysis indicated that $\mathrm{Al}$ and $\mathrm{Mg}$ atoms were mainly distributed on the outer coatings with mean compositions of $78 \% \mathrm{Al}$ and $22 \% \mathrm{Mg}$ for the potentiostatical electrodeposition sample (Fig. 5e) and $84 \% \mathrm{Al}$ and $16 \% \mathrm{Mg}$ for the galvanostatical one (Fig. 5d), respectively. It was suggested that the top coating formed at a constant current density had a slightly higher aluminum concentration than that obtained at a constant potential. Accordingly, it can be deduced that the constant current density is advantageous for the formation of uniform and coherent $\mathrm{Al}$ coatings. ${ }^{16}$ The $\mathrm{Al}$ contents (84.37\%, 78.32\%) in the present samples were comparable with that reported by $\mathrm{H}$. Yang. ${ }^{19}$

The corrosion resistances of the $\mathrm{Mg}$ alloy with $\mathrm{Al}$ coatings were adequately investigated by potentiodynamic polarization and electrochemical impedance spectroscopy (EIS). Fig. 6a displays the polarization curves of the three samples. The bare $\mathrm{Mg}$ alloy exhibits highly active dissolution performance, as displayed by curve 1 . Also, the anodic current increased rapidly and reached the limit of $0.1 \mathrm{~A} \mathrm{~cm}^{-2}$ in a short time when the potential overcame $E_{\text {corr }}$. However, the Al coatings could effectively slow down the corrosion of the $\mathrm{Mg}$ alloy, and passivation breakdown was observed in curves 2 and 3. The passive current densities of the coatings obtained with $-0.67 \mathrm{~V}$ and $-30.08 \mathrm{~mA}$ were close to $10^{-4}$ and $10^{-5} \mathrm{~mA} \mathrm{~cm}^{-2}$, respectively. This indicated that the dissolution rates were visibly suppressed as compared with that of the $\mathrm{Mg}$ alloy substrate. In addition, the coating obtained with $-30.08 \mathrm{~mA}$ manifested superior protective performance than that with $-0.67 \mathrm{~V}$. Fig. $6 \mathrm{~b}$ displays the Nyquist plots of the three samples. The single semicircle of these spectra demonstrates the one time constant equivalent circuit. The polarization resistances $\left(R_{\mathrm{p}}\right)$ of the $\mathrm{Mg}$ alloy, $-0.67 \mathrm{~V} \mathrm{Al}$ sample and $-30.08 \mathrm{~mA}$ sample were 406, 758 and $1267 \Omega$, respectively. Clearly, the $R_{\mathrm{p}}$ values of the Al coatings were much higher than that of the bare $\mathrm{Mg}$ alloy, suggesting the effective protection of $\mathrm{Al}$ coatings. The better protective behavior of the Al coating obtained with $-30.08 \mathrm{~mA}$ was ascribed to its continuous and compact structure compared to the loose and cracked structure of the Al coating obtained with $-0.67 \mathrm{~V}$ (Fig. 5).

Clearly, the Al coating could be obtained by this method. Unlike the electrodeposition process in a glove box, which isolates water and air in the process, the ionic liquid 


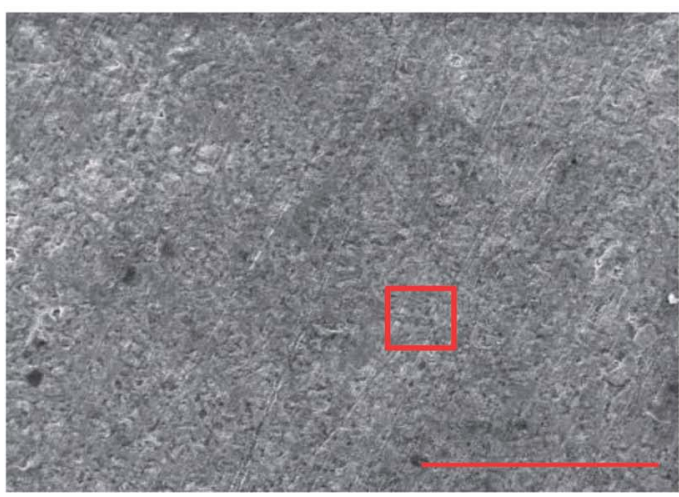

(a)

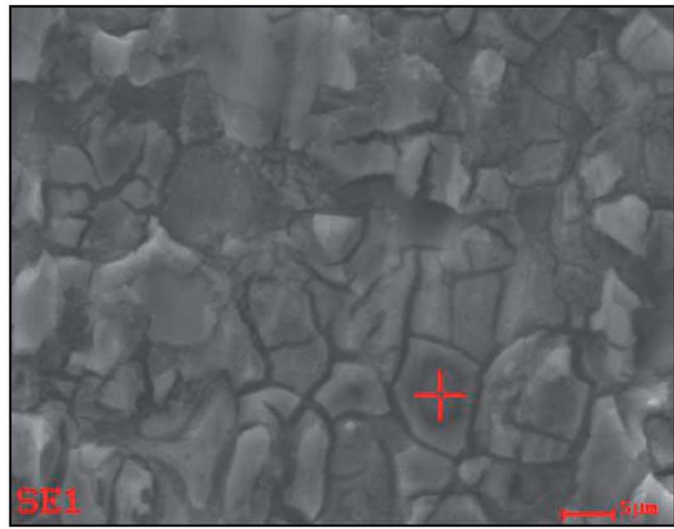

(c)

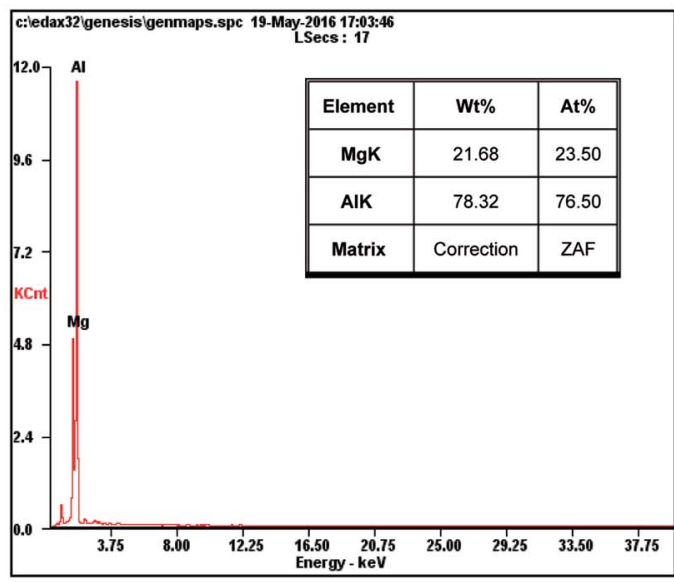

(e)

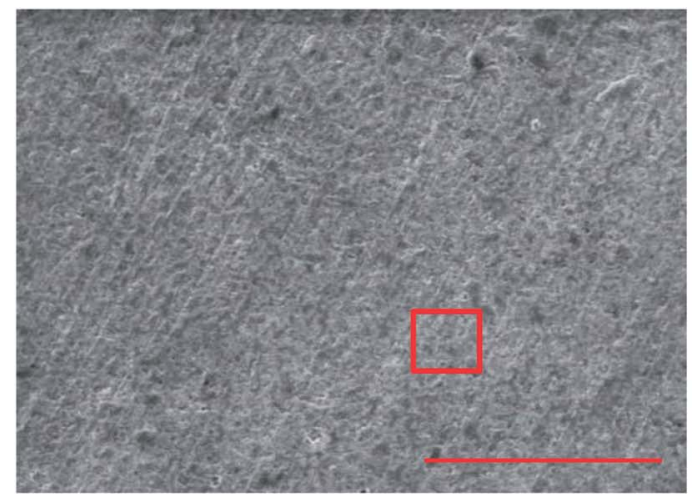

(b)

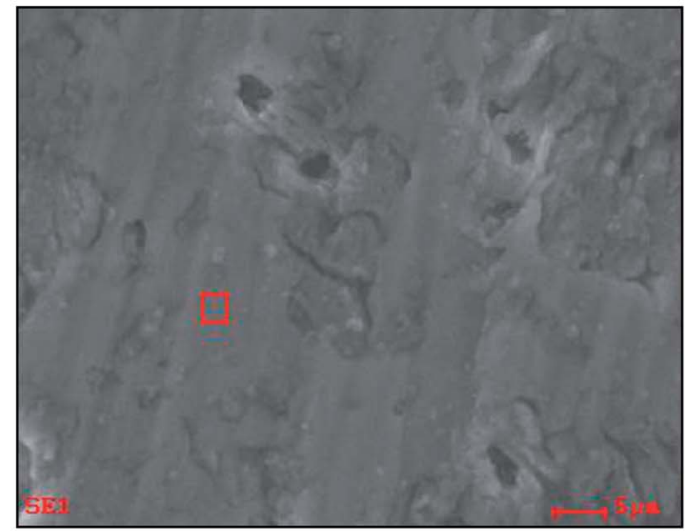

(d)

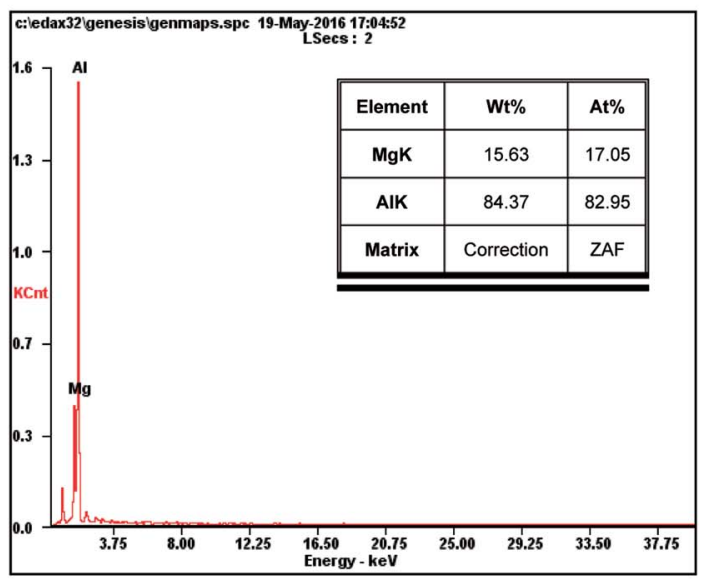

(f)

Fig. 5 SEM and EDS analyses of the coatings obtained with $-0.67 \mathrm{~V}(\mathrm{a}, \mathrm{c}$ and $\mathrm{e}$ ) and $-30.08 \mathrm{~mA}(\mathrm{~b}, \mathrm{~d}$ and $\mathrm{f})$. The scale bar of (a) and (b) is $500 \mu \mathrm{m}$.

preparation and electroplating process was carried out in air in the present method.

\section{Conclusion}

A simple method using the water-absorbent material combined with an organic protective film was proposed to guarantee the electrodeposition of $\mathrm{Al}$ on an $\mathrm{Mg}$ alloy (AZ91D) substrate from a first-generation ionic liquid $\mathrm{AlCl}_{3} /[\mathrm{Bmim}] \mathrm{Cl}(2: 1 \mathrm{~mol} \%)$ in air. In the preparation of ionic liquid, a $4 \mathrm{~A}$ molecular sieve was added to absorb the water infiltrated during the addition of chemicals. At the same time, undecane was added to form organic films on the liquid, which could prevent the infiltration of water and air efficiently. The electrodeposition experiment carried out with a constant current $(-30.08 \mathrm{~mA})$ led to the formation of a continuous and compact $\mathrm{Al}$ coating. The 


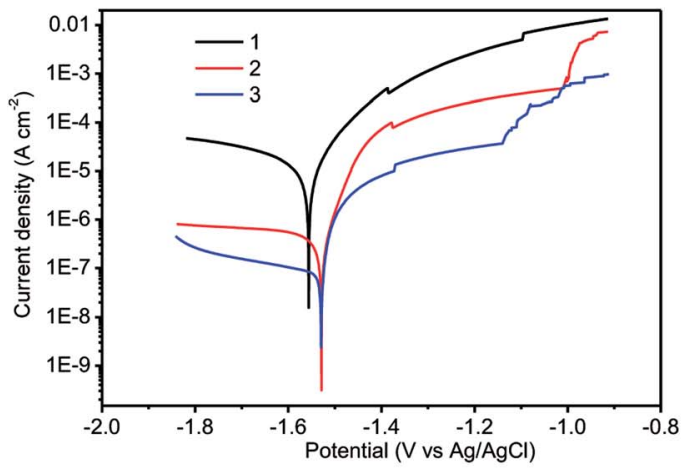

(a)

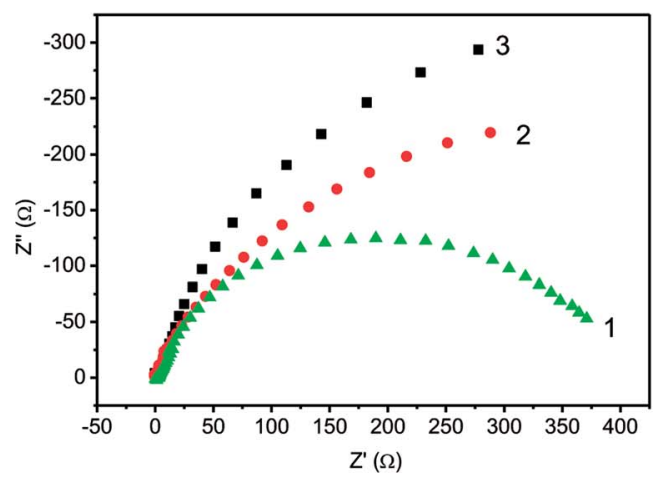

(b)

Fig. 6 Potentiodynamic polarization curves (a) and Nyquist plots (b) of the Mg alloy substrate (1), coatings obtained with $-0.67 \mathrm{~V}(2)$ and -30.08 $\mathrm{mA}$ (3). The measurements were performed in $3.5 \mathrm{wt} \% \mathrm{NaCl}$ solution.

proposed method has great potential to help realize the industrialization of $\mathrm{Al}$ electrodeposition on $\mathrm{Mg}$ alloys.

\section{Conflicts of interest}

There are no conflicts of interests.

\section{Acknowledgements}

This work was supported by the Special Fund for Agro-scientific Research in the Public Interest of China (No. 201503108) and the Science \& Technology Project of Hunan Province (No. 2017WK2091).

\section{References}

1 G. Hu, B. Xing, F. Huang, M. Zhong and D. Zhang, Effect of Y addition on the microstructures and mechanical properties of as-aged Mg-6Zn-1Mn-4Sn (wt\%) alloy, J. Alloys Compd., 2016, 689, 326-332.

2 F. Bu, Q. Yang, K. Guan, X. Qiu, D. Zhang, W. Sun, T. Zheng, X. Cui, S. Sun, Z. Tang, X. Liu and J. Meng, Study on the mutual effect of $\mathrm{La}$ and $\mathrm{Gd}$ on microstructure and mechanical properties of $\mathrm{Mg}-\mathrm{Al}-\mathrm{Zn}$ extruded alloy, J. Alloys Compd., 2016, 688, 1241-1250.

3 N. R. Brooks, S. Schaltin, K. Van Hecke, L. Van Meervelt, K. Binnemans and J. Fransaer, Copper(I)-containing ionic liquids for high-rate electrodeposition, Chem.-Eur. J., 2011, 17, 5054-5059.

4 A. Bakkar and V. Neubert, Electrodeposition onto magnesium in air and water stable ionic liquids: from corrosion to successful plating, Electrochem. Commun., 2007, 9, 2428-2435.

5 J.-K. Chang, S.-Y. Chen, W.-T. Tsai, M.-J. Deng and I.-W. Sun, Electrodeposition of aluminum on magnesium alloy in aluminum chloride $\left(\mathrm{AlCl}_{3}\right)$-1-ethyl-3-methylimidazolium chloride (EMIC) ionic liquid and its corrosion behavior, Electrochem. Commun., 2007, 9, 1602-1606.
6 F. Liu, Y. Deng, X. Han, W. Hu and C. Zhong, Electrodeposition of metals and alloys from ionic liquids, J. Alloys Compd., 2016, 654, 163-170.

7 S. Caporali, A. Fossati, A. Lavacchi, I. Perissi, A. Tolstogouzov and U. Bardi, Aluminium electroplated from ionic liquids as protective coating against steel corrosion, Corros. Sci., 2008, 50, 534-539.

8 M.-J. Deng, P.-C. Lin, J.-K. Chang, J.-M. Chen and K.-T. Lu, Electrochemistry of $\mathrm{Zn}(\mathrm{II}) / \mathrm{Zn}$ on $\mathrm{Mg}$ alloy from the $\mathrm{N}$-butyl$N$-methylpyrrolidinium dicyanamide ionic liquid, Electrochim. Acta, 2011, 56, 6071-6077.

9 P.-Y. Chen and C. L. Hussey, The electrodeposition of Mn and $\mathrm{Zn}-\mathrm{Mn}$ alloys from the room-temperature tri-1butylmethylammonium bis((trifluoromethane)sulfonyl) imide ionic liquid, Electrochim. Acta, 2007, 52, 1857-1864.

10 T.-Y. Huang, C. J. Marvel, P. R. Cantwell, M. P. Harmer and C. A. Schuh, Grain boundary segregation in Al-Mn electrodeposits prepared from ionic liquid, J. Mater. Sci., 2015, 51, 438-448.

$11 \mathrm{~F}$. Endres and S. Zein El Abedin, Air and water stable ionic liquids in physical chemistry, Phys. Chem. Chem. Phys., 2006, 8, 2101-2116.

12 R. Bomparola, S. Caporali, A. Lavacchi and U. Bardi, Silver electrodeposition from air and water-stable ionic liquid: an environmentally friendly alternative to cyanide baths, Surf. Coat. Technol., 2007, 201, 9485-9490.

13 A. Bakkar and V. Neubert, A new method for practical electrodeposition of aluminium from ionic liquids, Electrochem. Commun., 2015, 51, 113-116.

14 H. M. Abood, A. P. Abbott, A. D. Ballantyne and K. S. Ryder, Do all ionic liquids need organic cations? Characterisation of $\left[\mathrm{AlCl}_{2} \cdot \text { namide }\right]^{+} \mathrm{AlCl}_{4}{ }^{-}$and comparison with imidazolium based systems, Chem. Commun., 2011, 47, 3523-3525.

15 B. Li, C. Fan, Y. Chen, J. Lou and L. Yan, Pulse current electrodeposition of $\mathrm{Al}$ from an $\mathrm{AlCl}_{3}$-EMIC ionic liquid, Electrochim. Acta, 2011, 56, 5478-5482.

$16 \mathrm{~J}$. Tang and K. Azumi, Optimization of pulsed electrodeposition of aluminum from $\mathrm{AlCl}_{3}$-1-ethyl-3- 
methylimidazolium chloride ionic liquid, Electrochim. Acta, 2011, 56, 1130-1137.

17 S. Z. El Abedin, E. M. Moustafa, R. Hempelmann, H. Natter and F. Endres, Additive free electrodeposition of nanocrystalline aluminium in a water and air stable ionic liquid, Electrochem. Commun., 2005, 7, 1111-1116.

18 H. N. Nobuyuki Koura, A. Sato, S. Kumakura, K. Takeuchi, K. Ui, T. Tsuda and C. K. Loong, Electroless plating of aluminum from a room-temperature ionic liquid electrolyte, J. Electrochem. Soc., 2008, 155, D155-D157.

19 H. Yang, X. Guo, G. Wu, W. Ding and N. Birbilis, Electrodeposition of chemically and mechanically protective Al-coatings on AZ91D Mg alloy, Corros. Sci., 2011, 53, 381-387. 